\title{
A study on the lightning impulse breakdown voltages of palm oil and coconut oil by different methods
}

\begin{abstract}
In recent years, there have been a number of interests on the Palm Oil (PO) and Coconut Oil (CO) as a potential alternative dielectric insulating fluid in transformers which stimulate different types of studies on these oils properties. Among the important studies is the lightning impulse properties. This paper presents the investigation on the lightning impulse breakdown voltage of $\mathrm{PO}$ and $\mathrm{CO}$ under non-uniform electric field. The PO used in this study is Refined, Bleached and Deodorized Palm Oil (RBDPO) Olein type. The influence of the testing methods, rising-voltage and up-and-down are investigated at 2 gap distances for both oils. It was found that the lightning breakdown voltage performance for some of the RBDPO and $\mathrm{CO}$ are comparable to MO.
\end{abstract}

Keywords: Coconut oil; Dielectric insulating fluid; Impulse breakdown voltage; Nonuniform field; Palm oil 